Fanum

Sociológico

\section{Forum Sociológico}

Série II

37 | 2020

Número 37

\title{
Para uma sociologia dos crimes ambientais. Reflexões sobre o caso dos pesticidas em França
}

For a sociology of environmental crime. Reflections on the case of pesticides in France

Laurent Mucchielli

\section{(2) OpenEdition}

\section{Journals}

Edição electrónica

URL: https://journals.openedition.org/sociologico/9412

DOI: 10.4000/sociologico.9412

ISSN: 2182-7427

Editora

CICS.NOVA - Centro Interdisciplinar de Ciências Sociais da Universidade Nova de Lisboa

Edição impressa

Paginação: 19-26

ISSN: 0872-8380

\section{Refêrencia eletrónica}

Laurent Mucchielli, «Para uma sociologia dos crimes ambientais. Reflexões sobre o caso dos

pesticidas em França», Forum Sociológico [Online], 37 | 2020, posto online no dia 23 dezembro 2020, consultado o 29 março 2022. URL: http://journals.openedition.org/sociologico/9412 ; DOI: https://

doi.org/10.4000/sociologico.9412 


\title{
PARA UMA SOCIOLOGIA DOS CRIMES AMBIENTAIS. REFLEXÕES SOBRE O CASO DOS PESTICIDAS EM FRANÇA
}

\author{
FOR A SOCIOLOGY OF ENVIRONMENTAL CRIME. \\ REFLECTIONS ON THE CASE OF PESTICIDES IN FRANCE
}

\author{
Laurent Mucchielli \\ Laboratoire Méditerranéen de Sociologie, CNRS \& Aix-Marseille Université, França
}

\begin{abstract}
Resumo
A questão das catástrofes ambientais e sanitárias, causadas pelas actividades económicas humanas, tem sido cada vez mais divulgada desde os anos 70. Uma sociologia do ambiente e depois uma sociologia do risco desenvolveu-se nos Estados Unidos e depois na Europa. Mas só muito recentemente é que a sociologia do desvio se debruçou sobre estes temas, questionando a existência de práticas criminosas que, por vezes, desempenham um papel importante na perpetuação das ameaças. A sociologia do desvio inspira-se na tradição de investigação sobre a "criminalidade de colarinho branco" iniciada por Edwin Sutherland e, mais precisamente, na investigação sobre a criminalidade empresarial. Este artigo procura contribuir para a constituição e a problematização deste relativamente novo campo de investigação na Europa continental que, aqui, é ilustrado com o exemplo da poluição do solo e da água por pesticidas utilizados maciçamente na agricultura em França.
\end{abstract}

Palavras-chave: crimes ambientais, crimes corporativos, poluição do solo e da água, pesticidas

\begin{abstract}
The issue of environmental and health disasters caused by human economic activities has been increasingly publicized since the 1970s. Environmental sociology and then sociology of risk have been developed in the United States and then in Europe. But it is only very recently that the sociology of deviance has taken up these subjects, questioning the existence of delinquent practices that sometimes play a major role in the perpetuation of threats. It is inspired by the tradition of research on White Collar Crime initiated by Edwin Sutherland, and more precisely by research on Corporate Crime. This article attempts to contribute to the constitution and problematization of this relatively new field of research in continental Europe. It also illustrates it through the example of soil and water pollution by pesticides used massively in French agriculture.
\end{abstract}

Keywords: environnemental crime, corporate crime, soil and water pollution, pesticides

Nos Estados Unidos, a sociologia ambiental surgiu como um subcampo disciplinar nos anos 70 (Buttel, 1978; Catton \& Dunlap, 1979), por vezes com fortes ligações à crítica do capitalismo (Schnaiberg, 1980) ${ }^{1}$. Rapidamente deu origem a uma sociologia do risco que teve grande sucesso no Ocidente a partir dos anos 80 e foi sintetizada pela primeira vez no livro do sociólogo alemão Ulrich Beck, The Risk Society (2015 [1986]). Em França, nas ciências sociais, a partir dos anos 90 , as questões ambientais são primeiro investigadas pela ciência política, que as aborda enquanto "problema público" (Kalaora \& Vlassopoulo, 2013; Lascoumes, 1994; Lemieux \& Barthe, 1998), com ligação estreita às questões de saúde pública (Gilbert \& Henry, 2009; Jouzel, 2012) e de saúde no trabalho (Thébaud-Mony, Daubas-Letourneux, Frigul \& Jobin, 2012).

Mais recentemente, os sociólogos propuseram associar estas questões à que tradicionalmente ocupam o tema da "insegurança", elencando catástrofes sanitárias que afectam as populações, ou episódios de fraude e evasão fiscal que arruínam os Estados, 
como exemplo de tantas "inseguranças ignoradas" (Palidda, 2016). Em paralelo, a sociologia do desvio investiu igualmente nestes objetos, imputando-Ihes a qualidade de práticas criminosas (definidas como violações deliberadas das normas legais) que, por vezes, desempenham um papel importante na perpetuação das ameaças ambientais e sanitárias. A sociologia do desvio emergiu, assim, em consonância com a investigação sobre a criminalidade de colarinho branco (White Collar Crime) iniciada por Edwin Sutherland (Lascoumes \& Nagels, 2014; Mucchielli, 2018; Mucchielli \& Salle, 2019; Spire, 2013) $)^{2}$. Mais especificamente, Sutherland e seus seguidores inspiram-se na investigação sobre a criminalidade empresarial (Corporate Crime) e, a partir daí, estabelecem a ligação entre as questões ambientais e as questões da saúde, num movimento que veio dar origem à criminologia verde (Green Criminology), pelo menos desde o início dos anos 90, em Inglaterra e nos Estados Unidos (Bottoms, 1994; Lynch, 1990; South, 1998).

Os campos de estudo abrangidos por estas questões são, portanto, particularmente vastos e diversificados (Hall, Wyatt, South, Nurse, Potter \& Maher, 2016). Voltando ao caso da França, depois de termos estudado a poluição atmosférica pela indústria e pelos transportes (Mucchielli, 2020), discutiremos aqui o caso da poluição do solo e da água por pesticidas utilizados maciçamente na agricultura.

Os pesticidas são substâncias químicas destinadas a eliminar animais (insectos, vermes, lesmas e caracóis, roedores, aves...), fungos, várias plantas ou bactérias consideradas perigosas, nocivas ou simplesmente inestéticas. São utilizados maciçamente na agricultura, mas também no fabrico de muitos produtos para uso doméstico diário. Esta utilização é por vezes muito antiga e os efeitos de certos produtos são sentidos a longo prazo. Assim, os pesticidas são disseminados em todas as áreas do ambiente. Relativamente à sua perigosidade para os humanos ${ }^{3}$, os agricultores e outros profissionais directamente expostos aos seus efeitos são particularmente atingidos. No entanto e apesar de tais evidências, a protecção da saúde pública (e da biodiversidade) enfrenta lobbies económicos e interesses industriais muito poderosos, que desenvolvem estratégias de influência e corrupção até ao nível da agências nacionais e supranacionais responsáveis pelo controlo da saúde.

\section{A dimensão do problema em França}

Em França, o principal país agrícola da Europa, a maioria dos pesticidas autorizados são produtos fitofarmacêuticos utilizados na agricultura (herbicidas, insecticidas, fungicidas, reguladores do crescimento das plantas). A superfície agrícola utilizada corresponde a $53 \%$ da superfície total do país e conta com cerca de 430000 explorações agrícolas que empregam mais de 800000 pessoas (Graph'Agri, 2019). Por conseguinte, o país é um dos principais utilizadores mundiais de pesticidas, nomeadamente para a produção de feno e certos cereais (trigo, milho, colza...) e vinhas. Os principais pesticidas utilizados são o enxofre (vinha, árvores de fruto) e o glifosato. São manuseados por vários meios, desde a aplicação aérea até à aspersão manual, podendo assim contaminar o ar, a água e o solo.

Em 1999, o Ministério da Ecologia criou o programa de investigação "Avaliação e redução dos riscos relacionados com a utilização de pesticidas". A investigação sobre o assunto (ver Charbonnier, Ronceux, Carpentier, Soubelet \& Barriuso, 2015; bem como o relatório parlamentar de Martin \& Menuel, 2018) reforçou de forma clara o seu registo (sombrio).

Com efeito, a contaminação dos cursos de água com pesticidas é generalizada em França, principalmente por herbicidas na França continental e insecticidas nos territórios ultramarinos. Apenas 7\% da área agrícola francesa (maioritariamente localizada em áreas de baixa intensidade agrícola) está isenta destes contaminantes. "Em contrapartida, as regiões cerealíferas, de milho ou vitícolas, nomeadamente na bacia parisiense, em Adour-Garonne e ao longo do Ródano, ou as regiões com uma tradição hortícola, como a Martinica e Guadalupe, registam as concentrações mais elevadas de pesticidas" (Dubois \& Lacouture, 2014, p. 2). Mais especificamente, as regiões mais afectadas são as zonas vitícolas e cerealíferas. Os pesticidas mais frequentemente encontrados nos rios e nas águas subterrâneas são, em quase todos os casos, herbicidas. A substância activa mais frequentemente encontrada é a atrazina (INSERM, 2013), uma substância proibida porque é perigosa, mas, ainda assim, continua a ser a mais vulgarmente encontrada em certas regiões, em especial na água da torneira.

Em 2012, o Institut de veille sanitaire estudou a exposição da população francesa a determinadas substâncias activas pertencentes a três famílias de insecticidas. O resultado é que os componentes destes pesticidas estão presentes em 80 a $90 \%$ das amostras de urina. Ora, como os seus usos agrícolas e domésticos quase desapareceram, "esta absorção pela população em geral é essencialmente de origem alimentar, através do consumo de peixe, carne, leite e produtos lácteos, em resultado da bioacumulação destas moléculas nas gorduras animais" (INSERM, 2013). Mais uma vez, algumas regiões estão mais expostas do que outras. Na França metropolitana, a Bretanha, que é muito agrícola, é particularmente afectada. No ultramar, em Guadalupe e na Martinica, a presença de um pesticida particularmente tóxico (clordecona) - utilizado para controlar o gorgulho 
da banana até 1993, e que contaminou todo o solo, a água, a fauna e a flora - encontra-se em mais de $90 \%$ das amostras colhidas em homens adultos, com as concentrações mais elevadas observadas em antigos trabalhadores do sector da banana.

Este pesticida, classificado como um possível carcinogéno pela OMS desde 1979, causa cancro da próstata em adultos (Multigner, Brureau \& Blanchet, 2016) e, enquanto desregulador endócrino, aumenta o risco de nascimento prematuro e tem consequências prejudiciais para o desenvolvimento biopsicológico das crianças (Multigner, Rouget, Costet, Monfort, Blanchet, Kadhel, Bataille \& Cordier, 2018). Muitas vezes mencionada na imprensa local desde que uma acção de um denunciante surgiu no início dos anos 2000, "a questão parece esquecida na França metropolitana"4. Para este aparente esquecimento, talvez não seja displicente o facto de o antigo CEO da empresa que, no ultramar, comercializava a clordecona seja Yves Hayot, irmão de Bernard Hayot, uma das pessoas mais ricas de França, chefe do grupo especializado na distribuição em massa com o mesmo nome e gerente ou director de muitas empresas das indústrias da construção, dos transportes e automóvel, etc. Trata-se de uma das mais ricas famílias "békés" (crioulos brancos, descendentes dos colonos) que controla grande parte da economia das Índias Ocidentais francesas (Larcher, 2009; Monza, 2009).

\section{A perigosidade dos pesticidas}

Em 2013, o INSERM (principal organização de investigação médica francesa) realizou uma avaliação colectiva para fazer o balanço do conhecimento adquirido sobre a perigosidade dos pesticidas. Os investigadores e médicos recordaram, antes de mais, que, embora "um pesticida seja sempre tóxico para o alvo para o qual foi desenvolvido, [...] não há pesticida que seja totalmente específico de uma praga. Os organismos vivos, independentemente da sua posição taxonómica, partilham processos e mecanismos fisiológicos parcialmente comuns. Por conseguinte, um pesticida, quando utilizado para controlar uma praga, tem um potencial tóxico não previsto, mais ou menos extenso, para organismos não visados" (INSERM, 2013, p. 20). Os investigadores salientam também que estes efeitos indirectos "são muitas vezes desconhecidos ou descobertos muito depois de o pesticida em questão ter começado a ser utilizado".

A exposição a pesticidas pode acontecer durante o seu fabrico ou durante utilizações profissionais ou domésticas, mas também indirectamente através do ar, do contacto com superfícies contaminadas ou do consumo de água e alimentos. A contaminação pode ocorrer através da pele, da inalação, do tracto oral-digestivo. No caso das exposições profissionais, falamos geralmente de intoxicações directas ou agudas. Para a população em geral, falamos de envenenamento difuso ou crónico. "Em todos os casos [...] as principais questões dizem respeito aos efeitos de longo prazo da exposição a pesticidas, incluindo baixas doses de exposição, para a saúde" (INSERM, 2013, p. 21). Os riscos sanitários mais preocupantes ligados à absorção de pesticidas encontram-se entre os profissionais que os manipulam (a começar pelos agricultores), as populações imediatamente circundantes às explorações agrícolas e ainda, por via de difusão indirecta, entre as chamadas populações "sensíveis", como é o caso das mulheres grávidas, dos lactentes e das crianças pequenas, especialmente quando as exposições ocorrem in utero.

As patologias resultantes mais estudadas são as doenças e perturbações neurológicas, o comprometimento da função reprodutiva, as alterações do desenvolvimento e os cancros. No que respeita aos adultos, destacam-se:

1 - Os linfomas não-hodgkinianos "responsáveis por $2,4 \%$ e $2,7 \%$ de todas as mortes por cancro em homens e mulheres, respectivamente" (INSERM, 2013, p. 23),

2 - As leucemias agudas que representam $1 \%$ de todos os cancros incidentes, tal como as leucemias linfáticas crónicas (INSERM, 2013, p. 35),

3 - O mieloma múltiplo ou "doença de Kahler", responsável por $1,6 \%$ de todos os cancros incidentes em 2011 (INSERM, 2013, p. 45),

4 - A doença de Parkinson (doença neurodegenerativa mais comum após a doença de Alzheimer), que, neste âmbito, afecta, principalmente, agricultores que manuseiam pesticidas, assim como os seus vizinhos (Kab, Moisan, Spinosi, Chaperon \& Elbaz, 2018) $)^{5}$.

Finalmente, entre as crianças, as relações estabelecidas mais significativas ocorrem com casos de leucemia, de tumores cerebrais, de malformações congénitas e de neurodesenvolvimento em geral. Por seu turno, as mulheres grávidas com exposição profissional intensa vêem os riscos de morte fetal e malformações congénitas acrescidos (INSERM, 2013, p. 76). Isto está em consonância com o problema da desregulação endócrina causada pelos pesticidas, cuja exposição, mesmo em baixas doses, é particularmente perigosa durante os períodos fetais, perinatais e peripubertal (Fenichel, Brucker-Davis \& Chevalier, 2016).

\section{Consequências a longo prazo da exposição a pesticidas}

Já utilizados desde o século XIX, o uso mais intenso dos pesticidas (especialmente insecticidas) 
decorre do progresso da indústria química que aconteceu posteriormente, no século XX. Muitas destas substâncias químicas foram maciçamente utilizadas durante várias décadas, antes de os estudos científicos permitirem que a sua inocuidade para a saúde humana fosse posta em causa. Contudo, as consequências da exposição a pesticidas tornaram-se cada vez mais perceptíveis, tendo em vista, sobretudo, o longo prazo. Em razão disso, por exemplo, os bifenilos policlorados (PCB), que se encontram principalmente nos produtos animais (peixe, carne, ovos, produtos lácteos), estão proibidos em França desde 1987. No entanto, vinte anos mais tarde, em $13 \%$ das mulheres em idade fértil (18-45 anos) encontra-se, ainda, uma concentração de PCB totais acima dos limiares críticos propostos pela Agência Nacional de Segurança Sanitária (Fréry, Guldner, Saoudi, Garnier, Zeghnoun \& Bidondo, 2013).

Ainda mais maciçamente, o diclorodifeniltricloroetano (vulgarmente conhecido por DTT) foi amplamente utilizado a partir da Segunda Guerra Mundial para combater certas doenças (e.g., malária, tifo) e depois na agricultura. Em 1948, um cientista suíço recebeu o Prémio Nobel da Medicina pelo seu trabalho sobre a DDT e, em 1965, a OMS lançou um programa global de luta contra a malária, principalmente através da DDT. Porém, os primeiros avisos lançados sobre os seus efeitos devastadores na vida selvagem (especialmente aves e animais marinhos) e no corpo humano não tardaram. A partir da década de 1970, a maioria dos países proibiu-o na agricultura e, em 22 de Maio de 2001, 158 países assinaram a Convenção de Estocolmo sobre Poluentes Orgânicos Persistentes, que proíbe o DDT, entre outros poluentes químicos. Outro exemplo é a atrazina, um herbicida utilizado maciçamente na cultura do milho desde os anos 60, até ser proibido no início dos anos 2000 (2003 em França). Neste caso, um estudo de acompanhamento de uma coorte de 3500 mulheres grávidas, realizado na Bretanha entre 2002 e 2006, mostrou que as mulheres com vestígios de atrazina, ou uma das suas formas degradadas na urina, apresentavam um risco adicional de $50 \%$ de vir a ter um filho com baixo peso ao nascer e um risco ainda maior (70\%) de vir a ter um filho com um pequeno perímetro de cabeça ao nascer (Chevrier, Limon, Monfort, Rouget, Garlantézec, Petit, Durand \& Cordier, 2011).

\section{Protecção da saúde versus interesses industriais e comerciais: o caso Monsanto}

O reconhecimento da perigosidade dos pesticidas constitui, assim, um campo de batalha permanente entre a comunidade científica, as autoridades sanitárias, o poder político, as indústrias de fabrico e comercialização de pesticidas e alguns agricultores. Estas lutas têm lugar a todos os níveis, desde o local até ao internacional, passando pelo nacional. Nesta luta, a entidade mais hostil ao reconhecimento da perigosidade dos pesticidas é constituída pelos seus principais fabricantes. Tal como em outros domínios industriais (farmacêutico, alimentar, etc.), os produtores de pesticidas exercem pressão em grande escala e procuram ludibriar as avaliações científicas de muitas maneiras ${ }^{6}$.

O caso mais emblemático é o do grupo americano Monsanto, líder mundial no mercado das sementes e dos OGM. Este grupo industrial (que possui uma dúzia de instalações em França) especializou-se na produção de produtos químicos perigosos e na sua comercialização de forma enganosa, procurando proteger, na medida do possível, um comércio altamente questionável, enquanto tenta apresentar-se como "defensor do desenvolvimento sustentável" (Champion \& Gendron, 2004). Por exemplo, há muito que a Monsanto produz e comercializa hormonas de crescimento (utilizadas nomeadamente para estimular a produção de leite de vaca), bem como PCB (Polychlorinated biphenyls) que contaminaram a cidade de Anniston, Alabama, além de a sua utilização maciça - pelos militares americanos durante a Guerra do Vietname - ter causado centenas de milhares de doenças e malformações em crianças (Robin, 2008). Foi, aliás, nessa ocasião que o biólogo americano Arthur Galston cunhou o termo "ecocídio" (Neyret, 2015; Weisberg, 1970; Zierler, 2011).

O rol de acusações à Monsanto é, portanto, extenso. Outro herbicida comercializado pela empresa - Lasso - levou-a a ser condenada pela primeira vez em França, em 2012, acusada de ter feito batota na rotulagem dos seus produtos e de não cumprir o seu dever de alertar os utilizadores para os perigos do produto. Noutros casos o sucesso da contestação foi menor. Com efeito, apesar das numerosas acções intentadas em todo o mundo contra a empresa (e os seus múltiplos distribuidores nacionais) por ocultar os efeitos cancerígenos do manuseamento do glifosato (o herbicida mais vendido no mundo há várias décadas, comercializado sob a marca Round Up), a Monsanto continua a produzi-lo e a comercializá-lo (Robin, 2017) ${ }^{7}$.

Apesar do enorme efeito indirecto e do incalculável potencial de poluição a longo prazo do glifosato, dada a sua rápida degradação e penetração nas águas subterrâneas, há várias décadas que a Monsanto garante a sua manutenção no mercado, envidando todos os esforços (e.g., batota comercial, lobbying, contestações legais, corrupção) para impedir o reconhecimento oficial da perigosidade do pesticida ${ }^{8}$. Isto foi revelado pelo recente caso Monsanto Papers, quando, em Março de 2017, os tribunais norte-americanos levantaram a confidencialidade de documentos internos da empresa, mostrando as inúmeras pressões e estratégias de 
lobbying levadas a cabo, nomeadamente, sobre instituições de saúde norte-americanas, europeias e internacionais e a comunidade científica, para incentivar a publicação de estudos de credibilização do glifosato (Horel, 2018, pp. 128-147).

Em suma, apesar de todas estas controvérsias, só em 2015 é que o Centro Internacional de Investigação do Cancro da OMS reconheceu os efeitos "provavelmente cancerígenos" do glifosato. Contudo, o caso está longe de ter terminado, pois os efeitos do pesticida são globais e continuam a degradar a saúde humana e a biodiversidade em todo o mundo, causando um verdadeiro "ecocídio" que tem sido comparado ao caso do amianto (Robin, 2017). Assim, a par da luta contra os produtores oficiais de pesticidas de que a Monsanto é exemplo, permanecem lutas, porventura menos conhecidas e mediáticas, mas que se revelam ainda mais desiguais quando em causa estão organismos de controlo nacionais (como o Gabinete Central de Luta contra os Danos Ambientais e de Saúde Pública em França), ou internacionais (como o Organismo Europeu de Luta Antifraude) que, com dificuldade, tentam travar a contrafacção (especialmente na China) e o contrabando de pesticidas (Barroux \& Bollendorff, 2015).

\section{Um comboio pode esconder outro}

Embora a controvérsia sobre o glifosato tenha estado em pleno andamento nos últimos anos na Europa e, particularmente, em França, e embora a Monsanto tenha procurado virar a página ao ser voluntariamente comprada pela empresa farmacêutica e agroquímica alemã Bayer em 2016 (por 66 mil milhões de dólares), outro pesticida veio para a ribalta. Trata-se, mais precisamente, de um fungicida chamado SDHI (inibidor de succinato desidrogenase). Bloqueando a respiração dos seres vivos, a sua utilização substituiu maciçamente pesticidas anteriores na agricultura, desde a sua introdução no mercado por empresas agroquímicas (Monsanto-Bayer, BASF, Syngenta...) a partir de 2009. A 15 de Abril de 2018, um grupo de investigadores, cancerologistas, médicos e toxicólogos do $\mathrm{CNRS}^{9}$, INSERM $^{10}$, de várias universidades e do INRA ${ }^{11}$ publicou um artigo no jornal Libération, alertando para os perigos deste novo pesticida, utilizado em cerca de $70 \%$ do trigo mole e quase $80 \%$ da cevada de Inverno, bem como no tratamento de sementes e frutos (citrinos e uva) e na manutenção de relvados e campos de golfe (Collectif, 2018).

Sintetizando muitas pesquisas biomédicas anglo-saxónicas, o colectivo de cientistas mostrou que este fungicida não só destrói fungos e bolores que se desenvolvem nas plantas e frutos cultivados, como também os insectos que neles vivem e o solo e a água onde se desenvolvem e sobre os quais é pulverizado. Os investigadores salientaram que os perigos eram igualmente óbvios para os seres humanos, quer seja na forma directa (exposição) quer na indireta (através dos alimentos), resultando em encefalopatias em crianças pequenas, tumores do sistema nervoso, cancros do rim ou do aparelho digestivo... A tudo isto acresce que se observam ainda consequências do SDHI potenciadoras de outras doenças humanas, como sejam "a ataxia de Friedreich, a síndrome de Barth, a doença de Huntington, a doença de Parkinson e alguma astenozoospermia (perturbação do movimento espermático)" (Collectif, 2018).

Por último, os investigadores denunciaram o facto de as suas estruturas especializadas de investigação não terem sido consultadas, em momento algum, antes da emissão das autorizações de introdução no mercado pelas autoridades sanitárias, que, aparentemente, ficaram satisfeitas com os testes efectuados pelas próprias empresas industriais. Na mente de todos, a autoridade sanitária responsável por este laxismo é a Agência Nacional para a Segurança Alimentar, Ambiental e de Saúde no Trabalho (ANSES), estabelecimento público criado em 2010 e colocado sob a autoridade conjunta dos Ministérios da Saúde, da Agricultura, do Ambiente, do Trabalho e da Defesa do Consumidor. Em Setembro de 2019, no final da sua investigação, um jornalista acusou claramente o organismo público de estar sob a influência directa do lobby da indústria agroquímica (Nicolino, 2019).

Assim, embora a legislação que rege a utilização de pesticidas tenha sido timidamente reforçada veja-se o decreto de 29 de Dezembro de 2019, que fixa a distância mínima das casas que os agricultores devem respeitar para espalharem pesticidas ${ }^{12}-$, a poluição por estes produtos químicos continua a aumentar. Em 7 de Janeiro de 2020, o Ministério da Agricultura publicou estatísticas que indicam que o índice de intensidade da utilização de pesticidas (o número de doses unitárias [NODU]) utilizado em França tinha aumentado 24\% em 2018, em comparação com o ano anterior. Trata-se de uma verdadeira bofetada na cara do governo, uma vez que "um aumento tão espectacular nunca tinha sido registado desde a introdução deste indicador em 2008, no âmbito do primeiro plano Ecophyto"13. Introduzido no final do Grenelle de I'environnement (2007), este plano visava reduzir para metade a utilização de pesticidas em França em dez anos.

\section{Conclusão preliminar: é necessária mais investigação}

As questões levantadas neste artigo fazem eco dos debates que ocupam a sociologia do crime e da criminologia há cerca de vinte anos em Inglaterra e na América do Norte. Estão apenas a começar a ser investigados em França, onde estamos a lutar para 
sair de uma fase em que os "escândalos" políticos e mediáticos tendem a polarizar atitudes opostas de dramatização radical ou eufemismo. Os problemas ambientais e sanitários mencionados neste texto são, no entanto, antigos e as suas origens são bem conhecidas. Assim, o que surpreende é, antes, a sua persistência, ou mesmo a sua resistência, dada a escala crescente das mobilizações e regulamentações destinadas a combatê-los (Neyret, 2015).

De facto, a investigação salienta as contradições e opacidades em torno da implementação concreta das políticas públicas: "a gestão de muitos dossiers (como o gás de xisto ou os pesticidas) mostra o fosso que separa os princípios de abertura e muitas práticas administrativas e políticas que permanecem discricionárias" (Lascoumes, 2012, p. 125). O papel dos agentes administrativos dos organismos de controlo na gestão dos alertas de saúde só agora começa a ser estudado (Jouzel \& Prete, 2017), assim como o esforço mais geral de clarificação dos desafios e dos conflitos em torno da produção de conhecimentos especializados no domínio da saúde e do ambiente (Counil \& Henry, 2016; Henry et al., 2015). A investigação sobre o papel dos eleitos locais, que podem ajudar a controlar a acção dos poluidores, aliando-se aos agentes de controlo do Estado ou, pelo contrário, entrando em "lógicas de governação partilhada e de regulação territorial" com os industriais, está igualmente nos seus primórdios (Fournier \& Mattina, 2013). Além disso, em França e por enquanto, os sindicatos tradicionais de trabalhadores e agricultores parecem estar muito pouco mobilizados em França para os problemas ambientais. Por exemplo, neste contexto, a questão dos denunciantes e a necessidade da sua protecção ainda não foi estudada de forma sistemática. Quanto à mobilização dos cidadãos, sem o apoio do Estado ou dos eleitos locais, é inevitavelmente impotente e, tal como a nível mundial, os levantamentos tendem a permanecer dispersos e efémeros (Calvez, 2016).

No que diz respeito à sociologia da delinquência, há ainda muito terreno a investigar. Em termos de práticas industriais, seria importante poder analisar, com maior pormenor, as estratégias para "fazer passar práticas pouco éticas, ou mesmo delinquentes" (Spire, 2013), bem como as estratégias de resistência às pressões dos governos, dos media e da mobilização cidadã ${ }^{14}$. Do lado da administração pública, colocam-se questões quanto à natureza, eficácia e eficiência do controlo, à monitorização e às sanções aplicadas pelo Estado e pelas suas instituições em todos os domínios em causa (i.e., polícia, justiça, inspecção do trabalho, administração fiscal, organismos de monitorização e controlo ambiental e sanitário, etc. ${ }^{15}$ ).

Estes resultados representam, portanto, apenas um convite à investigação no domínio das ciências sociais, que frequentemente parecem estar alheados dos alertas emitidos por investigadores biomédicos independentes e mesmo por algumas investigações jornalísticas bem documentadas (Horel, 2015; Malet, 2017; Nicolino, 2019). Este parece ser um desafio para o futuro tão essencial como urgente, tendo em conta o estado do planeta e os desafios da saúde, seja para as gerações futuras, seja, como aqui procurámos deixar claro, para as gerações presentes.

\section{Notas}

1 O autor apresenta os seus mais calorosos agradecimentos aos revisores deste artigo. Os comentários permitiram melhorar consideravelmente o texto, tanto em termos de conteúdo como de forma.

2 O livro princeps de Sutherland foi traduzido recentemente no Brasil (Sutherland, 2015).

3 É claro que os pesticidas são os principais responsáveis pelo desaparecimento de insectos e aves (Martin \& Menuel, 2018, 31 sqq). Mais de meio século depois, o famoso livro da bióloga americana Rachel Carson Silent Spring ("Primavera Silenciosa", devido ao desaparecimento do canto dos pássaros, um achado na altura ligado à devastação do DDT) parece assim largamente profético (Chansigaud, 2012).

4 F. Vincent \& S. Foucart, "Scandale du chlordécone aux Antilles: I'État a fait en sorte d'en dire le moins possible", Le Monde, 7 de Junho de 2018; "Chlordécone: un scandale sanitaire", Le Monde, 29 de Setembro de 2018. Ver também Malcom (2019).

5 Em Fevereiro de 2020, uma equipa de investigadores franceses mostrou que os fungicidas contidos na água potável corrente (água da torneira), mesmo quando cumpridos os padrões europeus actuais, apresentavam o risco de agravar a doença de Alzheimer (Lafon, Wang, Arango-Lievano, Torrent, Salvador-Prince, Mansuy, Mestre-Francès, Givalois, Liu, Mercader, Jeanneteau, Desrumaux \& Perrier, 2020).

6 Em 2013, por exemplo, foi comunicado que 122 dos 209 peritos responsáveis pela análise dos dados fornecidos pela indústria na Agência Europeia de Segurança Alimentar (AESA) tinham ligações com o sector comercial em causa (Jobert, 2013, 2018).

7 Recorde-se que estes numerosos casos deram igualmente origem a uma mobilização internacional de cidadãos que tomou o nome de "Tribunal Monsanto" para julgar a firma por "violações dos direitos humanos" e "ecocídio", todos sob a presidência da jurista belga Françoise Tulkens. Estes "tribunais de opinião" parecem desempenhar um papel significativo no direito do ambiente (Cournil, 2016).

8 Graças à ONG francesa Générations Futures, membro da Pesticide Action Network, soube-se mesmo, em Fevereiro de 2020, que o TPL Hamburgo, um dos maiores laboratórios de ensaios em animais da Alemanha, que realiza estudos regulamentares em nome da indústria farmacêutica e química, é conhecido em todo o mundo e está registado para as "Boas Práticas de Laboratório" (BPL), tinha provavelmente falsificado estudos essenciais no processo de registo oficial de pesticidas, pelo menos desde 2005 ("Pesticidas: reported frauds in a laboratory evaluating their toxicity", Reporterre, 12 de Fevereiro de 2020 [em linha]). Pode-se, portanto, levantar a hipó- 
tese de um grupo de pessoas ter sido corrompido neste laboratório por grupos industriais como a Monsanto.

9 Centro Nacional de Investigação Científica.

10 Instituto Nacional de Saúde e Investigação Médica.

11 Instituto Nacional de Investigação Agrícola.

12 S. Mandard, "Pesticides: le gouvernement opte pour des distances très réduites entre zones d'épandage et habitations", Le Monde, 20 de Dezembro de 2019. Estas distâncias, entre 3 e 10 metros, são consideradas irrisórias por todas as associações de protecção do ambiente e da saúde pública. Em 25 de Fevereiro de 2020, nove organizações apelaram ao Conselho de Estado contra o decreto do governo (M. Astier, "Pesticides: le Conseil d'Etat appelé à trancher la question de l'épandage", Reporterre, 26 de Fevereiro de 2020 [em linha]).

13 S. Mandard, S. Foucart, "Le recours aux pesticides a connu une hausse spectaculaire en 2018", Le Monde, 7 de Janeiro de 2020.

14 Sobre os media, é significativo notar que, a 25 de Maio de 2020, 250 jornalistas escreveram ao Conselho Regional da Bretanha (a principal região agrícola francesa) para denunciar a pressão que enfrentam quando investigam a indústria alimentar (Good Planet Mag, 26 de Maio de 2020).

15 Um exemplo recente com um estudo sobre a resposta judicial a infracções ambientais envolvendo água e meios aquáticos (Barone, 2016).

\section{Referências bibliográficas}

Barone, S. (2016). Comment la justice traite les dommages écologiques. Une sociologie des acteurs judiciaires face aux atteintes à l'eau et aux milieux aquatiques. Montpellier: ONEMA/IRSTEA.

Barroux, R., \& Bollendorff, S. (2015). Pesticides connection. In Collectif Le Monde (Org.), Les prédateurs. La nature face au crime organisé (pp. 78-79). Paris: Ateliers Henri Dougier.

Beck, U. (2015 [1986]). Sociedade de risco mundial. Em busca da segurança perdida. Lisboa: Edições 70.

Bottoms, T. (1994). Environmental criminology. In M. Maguire, R. Morgan \& R. Reiner (Eds.), Oxford handbook of criminology (pp. 585-660). Oxford: Oxford University Press.

Buttel, F. H. (1978). Environmental sociology. A new paradigm?. The American Sociologist, 13, 252-256.

Calvez, M. (2016). Les risques de santé à l'épreuve des nuisances. Le cas des plaintes en santé environnementale. Recherches sociologiques et anthropologiques, 47(1), 187-203.

Catton, W. R., \& Dunlap, R. E. (1979). Environmental sociology. Annual Review of Sociology, 5, 243-273.

Champion, E., \& Gendron, C. (2004). Le "développement durable" selon Monsanto. Ecologie \& politique, 29(2), 121-133.

Chansigaud, V. (2012). Des hommes et des oiseaux. Paris: Delachaux et Niestlé.

Charbonnier, E., Ronceux, A., Carpentier, A.-S., Soubelet, H., \& Barriuso, E. (Eds.) (2015). Pesticides. Des impacts aux changements de pratiques. Paris: Éditions Quae.
Chevrier, C., Limon, G., Monfort, C., Rouget, F., Garlantézec, R., Petit, C., Durand, G., \& Cordier, S. (2011). Urinary biomarkers of prenatal atrazine exposure and adverse birth outcomes in the PELAGIE birth cohort. Environmental Health Perspectives, National Institute of Environmental Health Sciences, 119(7), 1034-1041.

Collectif (2018, 15 de Abril). Une révolution urgente semble nécessaire dans l'usage des antifongiques. Libération. Retirado de https://www. liberation.fr/debats/2018/04/15/une-revolution-urgente-semble-necessaire-dans-I-usage-des-antifongiques_1643539

Counil, É., \& Henry, E. (2016). Produire de l'ignorance plutôt que du savoir? L'expertise en santé au travail. Travail et emploi, 148(4), 5-29.

Cournil, C. (2016). Réflexions sur les méthodes d'une doctrine environnementale à travers l'exemple des tribunaux environnementaux des peuples. Revue juridique de l'environnement, (16), 201-218.

Dubois, A., \& Lacouture, L. (2014). Les pesticides dans les eaux douces. Indicateur territorial de développement durable. Ministère de l'écologie, du développement durable et de l'énergie Retirado de www.statistiques.developpement-durable.gouv.fr

Fenichel, P., Brucker-Davis, F., \& Chevalier, N. (2016). Perturbateurs endocriniens. Reproduction et cancers hormono-dépendants. La Presse Médicale, 45(1), 63-72.

Fournier, P., \& Mattina, C. (2013). Secours ou entrave à I'action publique? Les élus locaux face à l'État dans les territoires mono-industriels à risques. Sciences de la société, 90, 129-148.

Fréry, N., Guldner, L., Saoudi, A., Garnier, R., Zeghnoun, A., \& Bidondo, M.-L. (2013). Exposition de la population française aux substances chimiques de l'environnement. Saint Maurice: Institut de Veille Sanitaire.

Gilbert, C., \& Henry, E. (2009). Comment se construisent les problèmes de santé publique. Paris: La Découverte.

Graph'Agri. (2019). L'agriculture, la forêt, la pêche et les industries agroalimentaires. Paris: Ministère de l'agriculture et de I'alimentation.

Hall, M., Wyatt, T., South, N., Nurse, A., Potter, G. \& Maher, J. (2016). Greening criminology in the 21st century. Londres: Routledge.

Henry E., Gilbert C., Jouzel J.-N., Marichalar P. (dir.). (2015). Dictionnaire critique de l'expertise, Santé, travail, environnement. Paris: Presses de Sciences Po.

Horel, S. (2015). Intoxication. Perturbateurs endocriniens, lobbyistes et eurocrates. Paris: La Découverte.

Horel, S. (2018). Lobbytomie. Comment les lobbies empoisonnent nos vies et la démocratie. Paris: La Découverte.

INSERM. (2013). Pesticides. Effets sur la santé. Paris: Editions de I'INSERM.

Jobert, M. (2018, 7 de Fevereiro). Pesticides: Des méthodes d'évaluation très critiquées. Journal de l'environnement [em linha]. 
Jobert, M. (2013, 24 de Outubro). Les conflits d'intérêt minent la sécurité alimentaire européenne. Journal de l'environnement [em linha].

Jouzel, J.-N. (2012). Des toxiques invisibles. Sociologie d'une affaire sanitaire oubliée. Paris: Éditions de I'EHESS.

Jouzel, J.-N., \& Prete, G. (2017). La normalisation des alertes sanitaires. Le traitement administratif des données sur l'exposition des agriculteurs aux pesticides. Droit et société, 96(2), 241-256.

Kab, S., Moisan, F., Spinosi, J., Chaperon, L., \& Elbaz, A. (2018). Incidence de la maladie de Parkinson chez les agriculteurs et en population générale en fonction des caractéristiques agricoles des cantons français. Bulletin Épidémiologique Hebdomadaire, (8-9), 157-167.

Kalaora, B., \& Vlassopoulou, C. (2013). Pour une sociologie de l'environnement: Environnement, santé et politique. Seyssel: Champ Vallon.

Lafon, P.-A., Wang, Y., Arango-Lievano, M., Torrent, J., Salvador-Prince, L., Mansuy, M., Mestre-Francès, N., Givalois, L., Liu, J., Mercader, J. V., Jeanneteau, F., Desrumaux, C., \& Perrier, V. (2020). Fungicide residues exposure and $B$-amyloid aggregation in a mouse model of Alzheimer's disease. Environmental Health Perspectives, 128(1), 1-20.

Larcher, S. (2009). En quête du postcolonial. La crise des Antilles françaises et après.... Savoir/Agir, 2, 127-132.

Lascoumes, P. (1994). L'éco-pouvoir. Environnements et politiques. Paris: La Découverte.

Lascoumes, P. (2012). Action publique et environnement. Paris: Presses Universitaires de France.

Lascoumes, P. \& Nagels, C. (2014). Sociologie des élites délinquantes. Paris: Armand Colin.

Lemieux, C., \& Barthe, Y. (1998). Les risques politiques sous le regard des sciences du politique. Nouveaux chantiers, vieilles questions. Politix, 4, 7-28.

Lynch, M. (1990). The greening of criminology: A perspective on the 1990s. The Critical Criminologist, 3, 1-12.

Malcom, F. (2019). Une écologie décoloniale. Penser l'écologie depuis le monde caribéen. Paris: Seuil.

Malet, J.-B. (2017). L'empire de l'or rouge. Enquête mondiale sur la tomate d'industrie. Paris: Fayard.

Martin, D., \& Menuel, G. (2018). Rapport d'information de la mission d'information commune sur I'utilisation des produits phytopharmaceutiques. Paris: Assemblée Nationale.

Monza, R. (2009). Géopolitique de la crise guadeloupéenne: Crise sociale et/ou postcoloniale?. Hérodote, 4, 170-197.

Mucchielli, L. (2018). Sociologie de la délinquance (2.a ed.). Paris: Armand Colin.
Mucchielli, L. (2020). Environmental and corporate crimes. The case of polluting industries in France. In A. Balloni \& R. Sette (Eds.), Handbook of research on trends and issues in crime prevention, rehabilitation, and victim support (pp. 283-296). Hershey, IGI Global.

Mucchielli, L., \& Salle, G. (Eds.) (2019). La criminalité environnementale: État des lieux et perspectives. Déviance et société, 4, 469-479.

Multigner, L., Brureau, L., \& Blanchet, P. (2016). Le cancer de la prostate aux Antilles françaises: Etat des lieux. Bulletin Épidémiologique Hebdomadaire, (39-40),730-735.

Multigner, L., Rouget, F., Costet, N., Monfort, C., Blanchet, P., Kadhel, P., Bataille, H., \& Cordier, S. (2018). Chlordécone: Un perturbateur endocrinien emblématique affectant les Antilles françaises. Bulletin Épidémiologique Hebdomadaire, (22-23), 480-485.

Neyret, L. (Ed.) (2015). Des écocrimes à l'écocide. Le droit pénal au secours de l'environnement. Bruxelas: Bruylant.

Nicolino, F. (2019). Le crime est presque parfait. L'enquête choc sur les pesticides et les SDHI. Paris: Les Liens qui Libèrent.

Palidda, S. (Ed.) (2016). Governance of security and ignored insecurities in contemporary Europe. Londres: Routledge.

Robin, M.-M. (2008). Le monde selon Monsanto. De la dioxine aux OGM, une multinationale qui vous veut du bien. Paris: La Découverte.

Robin, M.-M. (2017). Le Roundup face à ses juges. Paris: La Découverte.

Schnaiberg, A. (1980). The environment. from surplus to scarcity. Nova Iorque: Oxford University Press.

Spire, A. (2013). Pour une approche sociologique de la délinquance en col blanc. Champ pénal/Penal field, $X$. Retirado de http://journals.openedition. org/champpenal/8582

South, N. (1998). Corporate and State crimes against the environment. Foundations for a Green perspective in European criminology. In V. Ruggiero, N. South \& I. Taylor (Eds.), The new European criminology (pp. 443-461). Londres: Routledge.

Sutherland, E. (2015). Crime de colarinho branco. Versão sem cortes. Rio de Janeiro: Revan.

Thébaud-Mony, A., Daubas-Letourneux, V., Frigul, N., \& Jobin, P. (2012). Santé au travail: Approches critiques. Paris: La Découverte.

Weisberg, B. (Ed.) (1970). Ecocide in Indochina: The ecology of war. São Francisco: Canfield Press.

Zierler, D. (2011). The invention of ecocide. Agent orange, Vietnam, and the scientists who changed the way we think about the environment. Atenas: University of Georgia Press.

Esta obra está licenciada com uma Licença Creative Commons Atribuição - 4.0 (CC BY 4.0). Recebido a 05/04/2020. Aceite para publicação a 29/05/2020

Laurent Mucchielli. Laboratoire Méditerranéen de Sociologie, CNRS \& Aix-Marseille Université, França. Email: mucchielli@mmsh.univ-aix.fr 